\title{
Antioxidant Activity of Syzygium samarangense L. and Their Endophytic Fungi
}

\author{
Budiono $^{1}$, Elfita ${ }^{2 *}$, Muharni ${ }^{2}$, Heni Yohandini ${ }^{2}$, Hary Widjajanti ${ }^{3}$ \\ ${ }^{1}$ Magister Program of Chemistry, Department of Chemistry, Faculty of Mathematics and Natural Sciences, \\ University of Sriwijaya, Palembang, South Sumatra, 30662 Indonesia \\ ${ }^{2}$ Department of Chemistry, Faculty of Mathematics and Natural Sciences, University of Sriwijaya, Inderalaya, \\ Ogan Ilir, South Sumatra, 30662 Indonesia \\ ${ }^{3}$ Department of Biology, Faculty of Mathematics and Natural Sciences, University of Sriwijaya, Inderalaya, \\ Ogan Ilir, South Sumatra, 30662 Indonesia
}

"Corresponding author email: elfita69@gmail.com

Received 10 Mar 2019; Accepted 30 May 2019; Available online 5 Jun 2019

\begin{abstract}
Leaves of jambu air (Syzygium samarangense L.) has been used by local residents as medicine for various diseases caused by free radical agents in human's body. This study aims to find a new source of antioxidants from medicinal plants and their endophytic fungi Syzygium samarangense leaves was fractionated by maceration method using gradient solvent i.e. $n$-hexane, ethyl acetate, and methanol. The antioxidant activity of the leaf fractions was determined using 1,1 diphenyl-2-picryl hydrazyl (DPPH) method. The chemical compound was isolated from active fraction by chromatographic techniques and their chemical structure was identified using spectroscopy techniques. The endophytic fungi was isolated from S. samarangense leaves and continued to cultivation in potato-dextrose broth (PDB) medium for four weeks. The medium was extracted using ethyl acetate and determined its antioxidant activity. Fungi's isolate with highest activity was analyzed to identify its molecular. Ethyl acetate fraction of $S$. samarangense leaves showed highest antioxidant activity. Spectroscopy analysis result concluded the isolated compound is 5,7-dihydroxy-6,8-dimethyl flavanone. Four endophytic fungi had been isolated form S. samarangense leaves. Antioxidant activity test showed that ethyl acetate extract of endophytic fungi BJA-1 has the highest value. Molecular identification of BJA-1 shows high homology with Lasiodiplodia venezuelensis strain CBS 129753.
\end{abstract}

Keywords: Syzygium samarangense, endophytic fungi, antioxidant activity, Lasiodiplodia venezuelensis

\section{INTRODUCTION}

Free radical is a highly reactive species that can interfere with cell integrity, react with the cell's structural component such as biological macromolecule for membrane building, and react with a functional components such as enzymes and DNA. In human's body, free radical triggers various degenerative disease including cancer, atherosclerosis, hypertension, rheumatoid, arthritis, diabetes, decrease of immunodeficiency system, and accelerates the aging process. Protection of the human body against free radical generally required a particular substance, namely antioxidant (Mary, George, Mathew, \& Varghese, 2017; Yadav, Yadav, \& Yadav, 2014).

Syzygium samarangense L. known as jambu air, is one of Myrtaceae's family (Mary et al., 2017). Most of part of this plant used for medicinal purpose. Its root, leaves, flowers, and fruits have been used traditionally to cure bronchitis, diabetes, cracked tongue, itchy, asthma, reduce swelling, infection of pathogenic bacteria, digest dysfunction, and kidney disease. Study confirms that extract of these plants shows antioxidant activity, antihyperglycemic cytotoxic, antibacterial, spasmolytic, and immunomodulatory. The $S$. samarangense leaves contain three $C$-methylated chalcone, flavonoid, gallic acid, triterpenoids, and volatile terpenoids (Edema \& Alaga, 2012; Khandaker, Alebidi, Hossain, Mat, \& Boyce, 2015; Khandaker \& Boyce, 2016; Insanu, Rmadhania, Halim, Hartati, \& Wirasutisna, 2018).

Endophytic is microorganism living inside plant tissue but it existence did not interfered the plant's life. The living organisms can be fungi or bacteria and has been associated since early of plant development (Kaur, Kaur, \& Kaur, 2018; Golinska et al., 2015). Either bacteria or fungi live in colony inside plant tissue. Almost all of plants type provides this kind of organism. Every plants has unique living organism that plays significant role as biocontrol agent in plant's development (Santoyo, Hagelsieb, Mosqueda, \& Glick, 2016).

Klimova, Rodríguez-Peña, \& Sánchez (2017) identified 46 kinds of the endophytic organism inside plant tissue. These organisms consist of 10 bacteria and 36 fungi. Among 36 kinds of fungi, 31 of them come from Ascomycota phylum. All of those organisms are capable of producing secondary metabolites with specific antioxidant activity. Endophytic fungi are a good a bioactive source due to its ability in producing bioactive in short period and does not require large growing area. 
This research is aimed to study the antioxidant activity of secondary metabolites from host plant dan from its endophytes. Results of this research can be used as scientific reference to find new antioxidant agent sources.

\section{EXPERIMENTAL SECTION}

\section{Materials and Instrumentation}

Fresh $S$. samarangense leaves were taken from Indralaya district, Ogan Ilir regency, South Sumatera. The identification was held at Biology Department, Sriwijaya University. Material for isolation: column chromatography using silica gel Merck 60G (70-230 mesh), TLC Kiesel gel $60 \mathrm{GF}_{254}, 0,25 \mathrm{~mm}, 20 \times 20 \mathrm{~cm}$ using Merck (Art.5554), a series of organics solvent with p.a. and technical grade (distilled before use), distilled water. Reagent for antioxidant activity from SigmaAldrich pure chemical industries United Kingdom: DMSO, DPPH, and standard ascorbic acid. Medium for isolation of endophytic fungi using Oxoid: PDA and PDB ( $200 \mathrm{~g}$ potato, $20 \mathrm{~g}$ dextrose, in $1 \mathrm{~L}$ of $\mathrm{H}_{2} \mathrm{O}$ ).

Instrumentation in the research were spectrophotometer ultraviolet Beck DU-7500, Perkin Elmer-FTIR spectrometer, ${ }^{1} \mathrm{H}-\mathrm{NMR}$ and ${ }^{13} \mathrm{C}-\mathrm{NMR}$ spectra on Agilent DD2 $\left({ }^{1} \mathrm{H}-500 \mathrm{MHz} ;{ }^{13} \mathrm{C}-125 \mathrm{MHz}\right.$ in $\left.\mathrm{CDCl}_{3}\right)$.

\section{Procedure \\ Extraction and antioxidant activity test of $S$. samarangense leaves}

1.5 kilograms of fresh $S$. samarangense leaves were cleaned and cut to pieces. The sample was dried in room temperature until its mass remain constant. The dried sample was pulverized and macerated using gradient solvent i.e. $n$-hexane, ethyl acetate and methanol. All macerate product was condensed using rotary evaporator to obtain concentrate extract of $n$-hexane, ethyl acetate and methanol fraction. Each fraction was tested against antioxidant activity using DPPH methods. The most active extract was isolated and then identification was carried out to obtain pure compounds.

\section{Antioxidant test using DPPH method}

Fraction obtained from previous procedure was dissolved to made $1000,500,250,125,62.5,31.25$, $15.625 \mu \mathrm{g} / \mathrm{mL}$ concentration. $0.2 \mu \mathrm{mL}$ of each concentration was added by $3.8 \mathrm{~mL} \mathrm{DPPH} 0,5 \mathrm{mM}$. The mixture was homogenized and left in the dark tube for 30 minutes. The absorption was measured using UVVis spectrophotometer at $\lambda_{\max } 517 \mathrm{~nm}$. In this test, ascorbic acid was used as a standard positive control and methanol as a negative control. Antioxidant activity can represent by the detention value of DPPH absorption, which was calculated through absorption inhibiting percentage of $\mathrm{DPPH}$ and $\mathrm{IC}_{50}$ value (Selvi, Joseph, \& Jayaprakasha, 2003; Elfita, Muharni, Munawar, \& Rizki, 2012).

$\%$ Inhibition $=\frac{\text { Control Abs. }- \text { sample Abs. }}{\text { Control Abs. }} \times 100$

\section{Isolation and identification of pure compund from an active extract}

The active extract was analyzed using thin layer chromatography method using solvent of various eluen. The extract $(20 \mathrm{~g})$ then was separated to vacuum column cromatography $(20 \mathrm{~cm} \times 8 \mathrm{~cm})$ with silica gel $(230-400$ mesh) as a stationary phase. The pre-absorption prepared sample was injected into the column and was eluted using gradient-polarity solvents, i.e., $n$-hexane-ethyl acetate $(10: 0 \rightarrow 0: 10)$ and ethyl acetate-methanol $(10: 0 \rightarrow 0: 10)$.). The eluate was collected in bottles and classified according to column fraction, which was determined by thin layer chromatography results. TLC analysis for each eluate result in 4 column fraction $(\mathrm{F} 1=7.4 \mathrm{~g} ; \mathrm{F} 2=3.2 \mathrm{~g}$; $\mathrm{F} 3=2.8 \mathrm{~g} ; \mathrm{F} 4=5.6 \mathrm{~g})$. Each column fraction was concentrated using rotary evaporator. F3 fraction was the one to process in open column cromatography using $n$ hexane-ethyl acetate-methanol as solvent and the result is 6 column fraction labelled as F3.1 to F3.6 was obtained. Column fraction F3.4 was re-separated in column cromatography and then subject to re-crystallization resulting $23 \mathrm{mg}$ pure compound as a yellow-pale powder which labelled as compound 1 . The pure compund was identified using UV, IR, ${ }^{1} \mathrm{H}-\mathrm{NMR},{ }^{13} \mathrm{C}-\mathrm{NMR}, \mathrm{HSQC}$, and HMBC spectroscopy and the result was compared with refference data.

\section{Sterilization of $S$. samarangense leaves and isolation of endophytic fungi}

Leaves sample were cleaned using flowing water for \pm 5 minutes and it surface was sterilized using ethanol $70 \%$ for \pm 3 minutes followed by aquadest for \pm 1 minute and rubbed with $\mathrm{HgCl}_{2}$ (mercury II chloride) $5 \%(\mathrm{~m} / \mathrm{v})$. After 1 minute, sample was rinsed using sterilized aquadest and cut sidewisely into several pieces. The sterilized pieces was placed on petri dish contain PDA supplemented with penicillin $\mathrm{G}$ (100 units $\mathrm{mL})$ and incubated at $37{ }^{\circ} \mathrm{C}$ for $2 \times 24$ hours. Sample was being observed every day for $3-7$ days until fungi was grow. Growth fungi colony in PDA medium which is showing different morphology such as shape, color and size was separated. The separation process was carried out by moving single type of colony to new PDA medium in a streak plate and incubated at $37^{\circ} \mathrm{C}$ for $2 \times 24$ hours. The pure fungi colony then prepared for working culture and stock culture by growing it in skewed PDA medium (Muharni, Fitrya, Ruliza, Susanti, \& Elfita, 2014; Barik, Tayung, Jagadev, \& Dutta, 2010; Khan et al., 2010).

\section{Selection of antioxidant activity from endophytic fungi extracts}

All strain of endophytic fungi was cultivated. Fungi inoculum $\left( \pm 10^{6}\right.$ spores $\left./ \mathrm{mL}\right)$ was inoculated $5 \%(\mathrm{v} / \mathrm{v})$ into $300 \mathrm{~mL}$ PDB medium then placed into 1-liter bottles and incubate at room temperature for four weeks. The medium contains secondary metabolites compound was partitioned into ethyl acetate and evaporated (Elfita, Munawar, Muharni, Pratiwi, \& Rahmadania, 2016). Finally, the concentrated medium proceeded to an antioxidant activity screening process to obtained active extract. 


\section{Identification of fungi}

The fungi was identified in the Biological Research Center-LIPI Cibinong. The fungi isolate was identified molecularly based on partial genetic analysis on Internal Transcribed Spacer (ITS) ribosomal DNA locus of fungi. Pure fungi cultures obtained (BJA-1) was cultivated in PDA medium for three days followed by growing on PDB medium for three days. Mycelium biomass of fungi was harvested, and its DNA was extracted using reagent nucleon PHYTOpure (Amersham LIFE SCIENCE). PCR amplification was conducted on ITS using primary ITS 4: 5'-TCC TCC GCT TAT TGA TAT GC - 3' and primary ITS 5: 5', - GGA AGT AAA AGT CGT AAC AAG G - 3' (White, Bruns, Lee, \& Taylor, 1990). Purification of PCR product was carried out by using PEG Precipitation methods (Hiraishi, Kamagata, \& Nakamura, 1995), followed by sequencing cycle. The results of sequencing were purified in Ethanol Purification Methods. Base sequence reading was analyzed using automated DNA Sequencer (ABI PRISM 3130 Genetic Analyzer (Applied Biosystems).

Raw data from sequence results was being trimming dan assembling using SeqTrace program. The sequence data (contig) was compared to determine the homology/ similarities molecularly with BLAST (http://ncbi.nlm.nih.gov/BLAST/). BLAST analysis is based on database nucleotide collection (nt/nr) which limited by sequence to type material. The BLAST analysis results in the form of an FASTA aligned sequences file with the extension txt taken from the highest percentage of similarity values. BLAST results were processed using the Clustal W application to produce files with MSF and PHYLIP extensions. PHYLIP files were processed with the Seqboot application with 1000 replicates. The results of the Seqboot application were processed into the DNAdist application with 1000 replicates and than into the Nieghbour application with 1000 replicates to produce an outree. This outree file was processed into the Consense application to produce the final file extension .phb. The phylogenetic tree was visualized by Treeview v1.4.3 program (Yohandini, Julinar, \& Muharni, 2017).

\section{RESULTS AND DISCUSSION}

Dried S. samarangense leaves as much as $615 \mathrm{~g}$ was obtained from $1.5 \mathrm{~kg}$ of fresh leaves. $500 \mathrm{~g}$ of powdered was extracted consecutively using $n$-hexane, ethyl acetate and methanol for $2 \times 24$ hours with three times repetitions. Concentrate of $31.7 \mathrm{~g} n$-hexane fraction, $28.2 \mathrm{~g}$ ethyl acetate fraction and $25.6 \mathrm{~g}$ methanol fraction were obtained after vacuum evaporation. All three fraction were tested for antioxidant activity, and results are shown in following Table 1. Ethyl acetate showing the highest antioxidant activity.
Table 1. $\mathrm{IC}_{50}$ values of $S$. samarangense leaves of all fractions, and ascorbic acid on antioxidant activity test using DPPH method.

\begin{tabular}{llr}
\hline Test sample & Fraction & \multicolumn{1}{c}{$\begin{array}{c}\text { IC50 } \\
(\boldsymbol{\mu g} / \mathbf{m L})\end{array}$} \\
\hline \multirow{2}{*}{ S. samarangense's leaves } & $n$-Hexane & 94.01 \\
& Ethyl acetate & 74.37 \\
Ascorbic Acid & Methanol & 929.22 \\
& Ascorbic Acid & 22.23 \\
\hline
\end{tabular}

The chemical compound from ethyl acetate fraction of S. samarangense leaves

Compound 1. A yellow-pale powder. UV spectra (MeOH) absorption at $\lambda_{\max }: 295$ and $341 \mathrm{~nm}$. UV spectra $(\mathrm{MeOH}+\mathrm{NaOH})$ absorption at $\lambda_{\max }: 339$ and $341 \mathrm{~nm}$. IR peak at $3271.8(\mathrm{OH}) .2925 .1$ (CH-aliphatic). 1633.2 $(\mathrm{C}=\mathrm{O}) .1607 .7-1468.8\left(\mathrm{C}_{6} \mathrm{H}_{5}\right)$. NMR $\left({ }^{1} \mathrm{H}-500 \mathrm{MHz} ;{ }^{13} \mathrm{C}-\right.$ $125 \mathrm{MHz}$; HSQC and $\mathrm{HMBC}$ in $\mathrm{CDCl}_{3}$ ) see Figure 1 and Table 2.

The ${ }^{1} \mathrm{H}-\mathrm{NMR}$ spectrum of compound $\mathbf{1}$ shows nine signals with 16 total protons. There were five aromatic protons appears at $\delta_{\mathrm{H}} 7.30-7.50 \mathrm{ppm}$. Furthermore, two methyl signals were detected at $\delta_{\mathrm{H}} 2.08(3 \mathrm{H} ; \mathrm{s})$ and 2.07 $(3 \mathrm{H} ; \mathrm{s})$. Moreover, there are three protons at chemical shift around 3-6 ppm and two hydroxyl protons.

According to phytochemical test, compound $\mathbf{1}$ is a flavonoid. The typical characteristic of flavonoid indicates by proton signal at low field $\delta_{\mathrm{H}} 12.27(1 \mathrm{H}$; s) which marks the existence of $-\mathrm{OH}$ chelat at $\mathrm{C}-5$ and chelated carbonyl carbon at C-4. Multiplicity pattern of these five aromatic protons implies it is an aromatic ring labeled as ring B. Ring A, therefore has no aromatic proton. The appearance of three proton signal at 3-6 ppm indicates ring $\mathrm{C}$ from compound $\mathbf{1}$ has no double bond neither has substituted hydroxyl groups. This suggests that the flavonoid obtained is a flavonone group compound.

${ }^{13} \mathrm{C}-\mathrm{NMR}$ spectra show 17 signals in which 15 of them belong to flavonone structure and 2 of them are methyl groups bound to ring $\mathrm{A}$. The compound $\mathbf{1}$ is identify as flavonone can be confirmed from the appearance of carbonyl carbon signals at $\delta_{\mathrm{C}} 196.6 \mathrm{ppm}$. The spectrum also shows that the compound has three oxyaryl carbon atoms $(=\mathrm{C}-\mathrm{O})$ that are at $\delta_{\mathrm{C}} 159.5 ; 157.8$ and $161.0 \mathrm{ppm}$. It indicates the existence of two hydroxyl groups at flavonoid structure, which bound to ring A. Identification of carbon and proton signals furthermore were set according to NMR 2D spectrum (Table 2). HMQC spectrum was used to idetify carbon signals which bound to $\mathrm{H}$ and showing $\mathrm{H}-\mathrm{C}$ correlation having distance by two or three bonds.

According to ${ }^{1} \mathrm{H}-\mathrm{NMR},{ }^{13} \mathrm{C}-\mathrm{NMR}, \mathrm{HMQC}$, and HMBC spectrum obtained and compared to the reference, it can be concluded that compound $\mathbf{1}$ is 5,7-dihydroxy 6,8-dimethyl flavanone (Figure 2). The molecular formula is $\mathrm{C}_{17} \mathrm{H}_{16} \mathrm{O}_{4}$ with $\mathrm{DBE}=10$. 

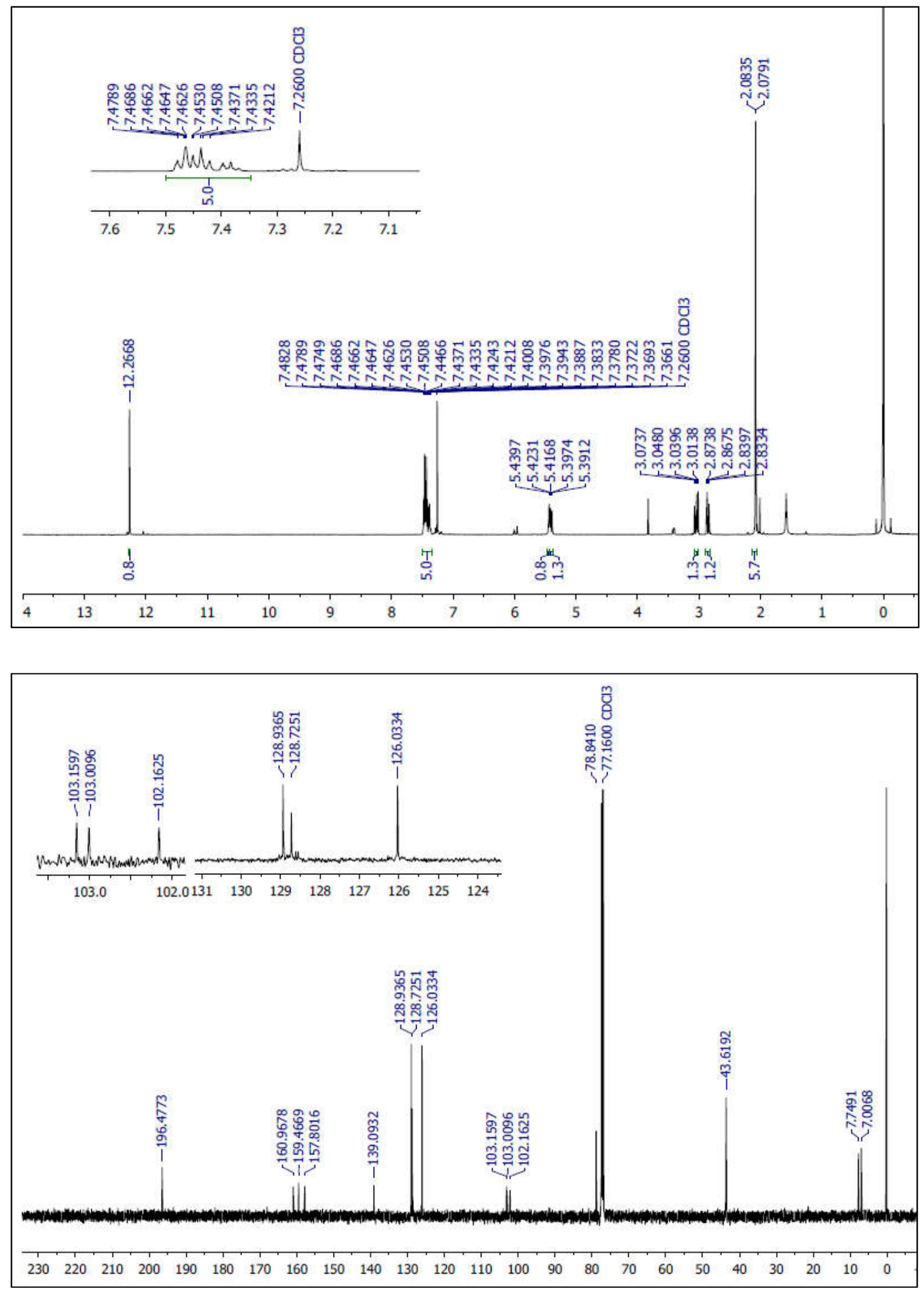

Figure 1. $500 \mathrm{MHz}{ }^{1} \mathrm{H}-\mathrm{NMR}$ and $125 \mathrm{MHz}{ }^{13} \mathrm{C}-\mathrm{NMR}$ spectra of compound $\mathbf{1}$ in $\mathrm{CDCl}_{3}$. 
Table 2. NMR data of Compound 1 recorded at ${ }^{1} \mathrm{H}-500 \mathrm{MHz} ;{ }^{13} \mathrm{C}-125 \mathrm{MHz}$ in $\mathrm{CDCl}_{3}$ and $1 *$ (5,7-dihydroxy-6,8dimethyl flavanone: recorded at ${ }^{1} \mathrm{H}-500 \mathrm{MHz} ;{ }^{13} \mathrm{C}-125 \mathrm{MHz}$ in $\mathrm{CD}_{3} \mathrm{OD}$ ) (Memon et al., 2015)

\begin{tabular}{|c|c|c|c|c|}
\hline $\begin{array}{c}\text { Position } \\
\text { of C }\end{array}$ & $\begin{array}{c}\delta c \text { ppm } \\
1 \\
\end{array}$ & $\begin{array}{c}\delta c \underset{p p m}{1 *} \\
\end{array}$ & $\delta_{H} \operatorname{ppm}(\Sigma H$. multiplicity. $J(\mathrm{~Hz}))$ & $\begin{array}{c}\text { HMBC } \\
1\end{array}$ \\
\hline 2 & 78.8 & 78.6 & $5.42(1 \mathrm{H} ; \mathrm{dd} ; \mathrm{J}=3.15 ; 3.15 \mathrm{~Hz})$ & \\
\hline 3 & 43.6 & 42.82 & $\begin{array}{l}3.04(1 \mathrm{H} ; \mathrm{dd} ; \mathrm{J}=3.15 ; 12.85 \mathrm{~Hz}) \\
2.84(1 \mathrm{H} ; \mathrm{dd} ; \mathrm{J}=12.85 ; 3.15 \mathrm{~Hz})\end{array}$ & $78.8 ; 196.5$ \\
\hline 4 & 196.5 & 196.6 & & \\
\hline 5 & 159.5 & 163.0 & & \\
\hline 6 & 102.2 & 102.8 & & \\
\hline 7 & 161.0 & 162.8 & & \\
\hline 8 & 103.0 & 101.9 & & \\
\hline 9 & 157.8 & 158.9 & & \\
\hline 10 & 103.2 & 103.5 & & \\
\hline 1 ' & 139.1 & 139.4 & & \\
\hline $2^{\prime}$ & 128.9 & 128.3 & $7.42(1 \mathrm{H} ; \mathrm{m})$ & $128.9 ; 139.1$ \\
\hline $3^{\prime}$ & 126.0 & 125.8 & $7.46(1 \mathrm{H} ; \mathrm{m})$ & $126.0 ; 128.7$ \\
\hline $4^{\prime}$ & 128.7 & 128.0 & $7.40(1 \mathrm{H} ; \mathrm{m})$ & 126.0 \\
\hline 5 & 126.0 & 125.8 & $7.46(1 \mathrm{H} ; \mathrm{m})$ & $126.0 ; 128.7$ \\
\hline 6 & 128.9 & 128.3 & $7.42(1 \mathrm{H} ; \mathrm{m})$ & $128.9 ; 139.1$ \\
\hline $6-\mathrm{CH} 3$ & 7.7 & 6.75 & $2.08(3 \mathrm{H} ; \mathrm{s})$ & $161.0 ; 159.5 ; 102.2$ \\
\hline $8-\mathrm{CH} 3$ & 7.0 & 6.0 & $2.07(3 \mathrm{H} ; \mathrm{s})$ & $103.0 ; 157.8$ \\
\hline $5-\mathrm{OH}$ & & & $12.27(1 \mathrm{H} ; \mathrm{s})$ & $103.2 ; 159.5$ \\
\hline 7-OH & & & $5.44(1 \mathrm{H} ; \mathrm{s})$ & \\
\hline
\end{tabular}
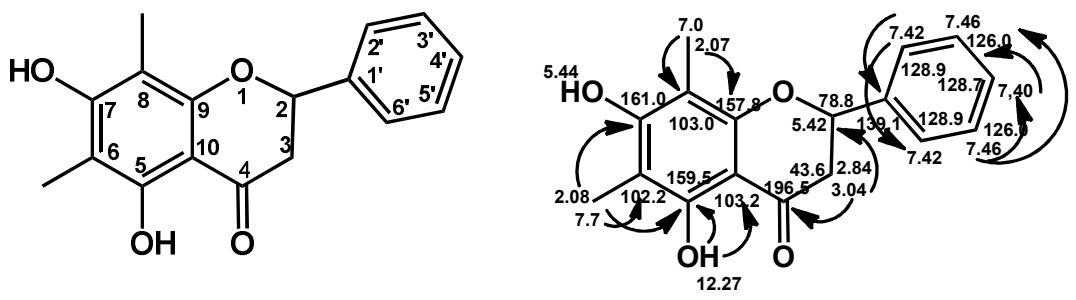

Figure 2. Structure of 5,7-dihydroxy 6,8-dimethyl flavanone and HMBC correlation

Result of antioxidant test shows that compound $\mathbf{1}$ is inactive with $\mathrm{IC}_{50}$ value $>100 \mu \mathrm{g} / \mathrm{mL}$. During $\mathrm{DPPH}$ measurement, reaction occurs between radical species of DPPH and tested compound. The absorption spectrum of residual radical species of DPPH after react with substrat was observed. Molecular structure of a compound affects its antioxidant activity. Compounds from flavonoid groups has abundant hydroxyl group which plays significant roles to antioxidant activity. Antioxidant activity increases if the compound has a unit known as cathecol or 1,2-dihydroxyfenil. Compound with cathecol unit or 1,2-dihydroxyfenil is more easily experience proton abstraction by free radical to form more stable radical. This stability established because of free radical forms intramolecular hydrogen bond with hydroxyl and diketones groups by its side. Like wise, compound with hydroxyl groups at para position against carbonyl group has proton easily abstracted by free radical to form more stabil radicals. This stability occurrence is caused by distribution and delocalization of electrons. The double bond and carbonyl groups in basic structure with heterocyclic rings will enhance its antioxidant activity. The radical stabilization was created through conjugation and electron delocalization (Procházková, Boušová, \& Wilhelmová, 2011; Brunetti et al., 2013; Sawai \& Sakata, 1998; Heim, Tagliaferro, \& Bobilya, 2002). However, compound 1 from flavonoid groups has least hydroxyl group in addition to no double bond on its heterocylclic ring. Moreover, the existence of chelated hydroxyl group along with carbonyl makes proton abstraction by free radical to form more stable radical is more difficult.

\section{Antioxidant activity of endophytic fungi}

Four endophytic fungi were isolated from $S$. samarangense leaves and were labeled as BJA1 - BJA4. The fungi was stored in petri dish contains medium as working culture and stock culture for colony shapes observation. Each fungus isolate cultivated in $3 \times 300 \mathrm{~mL}$ liquid PDB medium for four weeks. Partition extraction of cultivation medium conducted with ethyl acetate were able to yields $1.47 ; 1.62 ; 1.75$; and $1.34 \mathrm{~g}$ concentrate extracts respectively. Four fungi extracts were tested for antioxidant activity. The $\mathrm{IC}_{50}$ value of all $S$. samarangense leaves fractions, and ethyl acetate extract of endophytic fungi fraction using DPPH methods is display in Table 3. 
Table 3. $\mathrm{IC}_{50}$ values of ethyl acetate extracts of endophytic fungi isolated from $S$. samarangense leaves and ascorbic acid on antioxidant activity test using DPPH method.

\begin{tabular}{llr}
\hline Test sample & \multicolumn{1}{c}{ Fraction } & $\begin{array}{r}\text { IC50 } \\
(\boldsymbol{\mu g} / \mathbf{m L} \mathbf{)}\end{array}$ \\
\hline \multirow{3}{*}{ Endophytic } & Ethyl acetate BJA-1 & 49.96 \\
fungi & Ethyl acetate BJA-2 & 852.86 \\
\multirow{2}{*}{ Ascorbic Acid } & Ethyl acetate BJA-3 & 84.86 \\
& Ethyl acetate BJA-4 & 616.08 \\
& Ascorbic Acid & 22.23 \\
\hline
\end{tabular}

Endophytic fungi cultivation medium was effectively extracted by using ethyl acetate to isolate a secondary metabolites compound from endophytic fungi. Ethyl acetate solvent is selectively able to extract phenolic compound with low molecular mass and polyphenol with high molecular mass (Yadav et al., 2014; Khiralla et al., 2015). $\mathrm{IC}_{50}$ value at Table 1 confirms that ethyl acetate extract of endophytic fungi, BJA-1 is more active than leaves extract and seconder metabolite of its host plant.

Medicinal plants usually contain endophytic fungi which produce identic antioxidant activity in its secondary metabolites. Syzygium samarangense is one of the medicinal plants widely used in Indonesia, and some other countries contain various phytochemical compound such as saponins, alkaloids, flavonoids, tannins, phenolic, glycosides and terpenoid which contribute to its properties (Edema \& Alaga, 2012; Madhavi Ram, 2015).

\section{Identification of endophytic fungi}

The result of identification according to phylogenetic tree built in 1000 bootstrap replicates shows strain BJA-1 has highest homology with Lasiodiplodia venezuelensis strain CBS 129753 (Figure 3). Sequence of base area ITS rDNA: Contig BJA-1:

TAGGTGAACCTGCGGAAGGATCATTACCGAGTTC TCGAGCTCCGGCTCGACTCTCCCACCCTTTGTGA ATGTACCTCTGTTGCTTTGGCGGCCCCGGCCGCC AGAGGACCTTCAAACTCCAGTCAGTGAACGCAG ACGTCTGAAAACAAGTCAATAAACTAAAACTTTC AACAACGGATCTCTTGGTTCTGGCATCGATGAAG AACGCAGCGAAATGCGATAAGTAATGTGAATTG CAGAATTCAGTGAATCATCGAATCTTTGAACGCA CATTGCGCCCCTTGGTATTCCGGGGGGCATGCCT GTTCGAGCGTCATTACAACCCTCAAGCTCTGCTT GGCATTGGGCTCCGTCCTCACTGCGGACGCGCCT CAAAGACCTCGGCGGTGGCTGTTCGGCCCTCAAG CGTAGTAGAATACACCTCGCTTTGGAGCGGTCGG CGTCGCCCGCCGGACGAACCTTCTGAACTTTTCT CAAGGTTGACCTCGGATCAGGTAGGGATACCCG CTGAACTTA

Molecular identification and analysis with phylogenetic tree of BJA-1 shows high homology with Lasiodiplodia venezuelensis strain CBS 129753. This proves that endophytic fungi is capable to produce secondary metabollites with higher biological activity than its host. The Lasiodiplodia venezuelensis strain is recommended for further investigations.

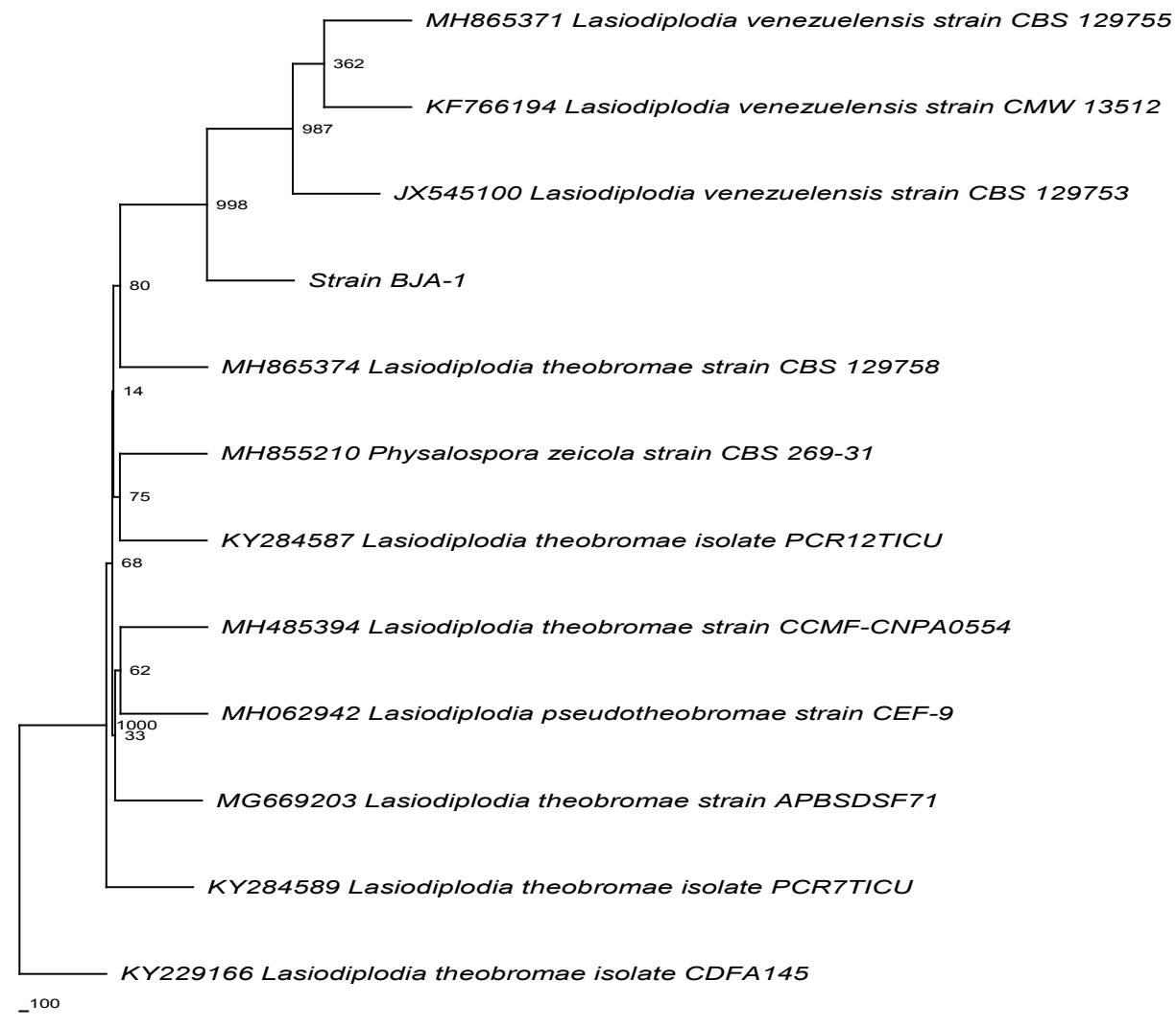

Figure 3. Phylogenetic tree of strain BJA-1 was visualized by Treeview program with 1000 bootstrap replicates 
Bioactive compound exploration from endophytic fungi has the advantage of short lifespan and compound availability to produce in large scale through the fermentation process. Isolation of bioactive compound from host plants has many obstacles because the scarcity of host plant and its relatively long life cycle. Hence the endophytic fungi have good prospect as a source to discover new antioxidant compound.

\section{CONCLUSIONS}

In this study, a pure compound from the active fraction of antioxidant has been found, but the compound is not antioxidant active. Further studies are needed to isolate the secondary metabolites of antioxidants found in the ethyl acetate fraction of the leaves of $S$. samarangense. This study also revealed the presence of secondary metabolites that have antioxidant activity produced by Lasiodiplodia venezuelensis endophytic fungus strain CBS 129753 from $S$. samarangense leaves. Further studies are needed to isolate and purify responsible bioactive compounds as antioxidants in ethyl acetate extract of endophytic fungus. These findings indicate that endophytic fungi from antioxidant plants could be potential for a source of antioxidant compounds.

\section{ACKNOWLEDGMENTS}

Author delivers high gratitude to Sriwijaya University, which has funding this research through Penelitian Unggulan Profesi 2018.

\section{REFERENCES}

Barik, B.P., Tayung, K., Jagadev, P.N., \& Dutta, S.K. (2010). Phylogenetic placement of an endophytic fungus Fusarium oxysporum isolated from Acorus calamus rhizomes with antimicrobial activity. European Journal of Biological Sciences, 2, 8-16.

Brunetti, C., Martina, D., Ferdinando, M.D., Fini, A., Pollastri, S., \& Tattini, M. (2013). Flavonoids as antioxidants and developmental regulators: relative significance in plants and humans. International Journal of Molecular Sciences, 14, 3540-3555.

Edema, M.O., \& Alaga, T.O. (2012). Comparative evaluation of bioactive compounds in Hibiscus sabdariffa and Syzygium samarangense juice extracts. African Crop Science Journal, 20 (3), 179-187.

Elfita, E., Muharni, M., Munawar, M., \& Rizki, R. (2012). Isolation of antioxidant compound from endophytic fungi Acremonium sp from the twigs of Kandis Gajah (Garcinia griffithii T, Anders). Makara of Science Series, 16 (1), 46-50.

Elfita, E., Munawar, M., Muharni, M., Pratiwi, G., \& Rahmadania, R. (2016). A benzoyl compound isolated from endophytic fungi of kandis gajah (Garcinia griffithii) and asam kandis (Garcinia cowa). Makara Journal of Science, 20 (4), 18-23.

Golinska, P., Wypij, M., Agarkar, G., Rathod, D., Dahm, H., \& Rai, M. (2015). Endophytic actinobacteria of medicinal plants: Diversity and bioactivity. Antonie Van Leeuwenhoek International Journal of General, 108 (2), 267-289.
Heim, K.E., Tagliaferro, A.R., \& Bobilya, D. J. (2002). Flavonoid antioxidant: chemistry, metabolism and structure-activity relationships. Journal of Nutritional Biochemistry, 13, 572-584.

Hiraishi, A., Kamagata, Y., \& Nakamura, N. (1995). Polymerase chain reaction amplification and restriction fragment length polymorphism analysis of $16 \mathrm{~S}$ rRNA genes from methanogens. Journal of Fermentation and Bioengineering, 79, 523-529.

Insanu, M., Rmadhania, Z.M., Halim, E.N., Hartati, R., \& Wirasutisna, K.R. (2018). Isolation of 5,7dihydroxy, 6,8-dimethyl flavanone from Syzygium aqueumwith its antioxidant and xanthine oxidase inhibitor activities. Pharmacognosy Research, 10 (1), 60-63.

Kaur, J., Kaur, R., \& Kaur, A. (2018). Evaluation of antidiabetic and antioxidant potential of endophytic fungi isolated from medicinal plants. International Journal of Green Pharmacy, 12 (1), 6-12.

Khan, R., Shahzad, S., Choudhary, M.I., Shakeel, A., Khan, S.A., \& Ahmad, A. (2010). Communities of endophytic fungi in medicinal plant Withania somnifera. Pakistan Journal of Botany, 42 (2), 1281-1287.

Khandaker, M.M., Alebidi, A.I., Hossain, A.S., Mat, N., \& Boyce, A.N. (2015). Physiological and biochemical properties of three cultivars of wax apple (Syzygium samarangense [Blume] Merrill \& L.M. Perry) fruits. Journal of Sustainability Science and Management, 10 (1), 66-75.

Khandaker, M.M., \& Boyce, A.N. (2016). Growth, distribution and physiochemical properties of wax apple (Syzygium samarangense): A Review. Australian Journal of Crop Science, 10 (12), 16401648.

Khiralla, A., Mohamed, I., Thomas, J., Mignard, B., Spina, R., Yagi, S., \& Mattar, L.D. (2015). A pilot study of antioxidant potential of endophytic fungi from some Sudanese medicinal plants. Asian Pacific Journal of Tropical Medicine, 8 (9), 701704.

Klimova, E.M., Rodríguez-Peña, K., \& Sánchez, S. (2017). Endophytes as sources of antibiotics. Biochemical Pharmacology, 134, 1-17.

Madhavi, M., \& Ram, M.R. 2015. Phytochemical screening and evaluation of biological activity of root extracts of Syzygium samarangense. International Journal of Research in Pharmacy and Chemistry, 5 (4), 753-763.

Mary, L.M.K., George, N.S.P., Mathew, N., \& Varghese, S.E. 2017. Antioxidant activity of wax jambu. European Journal of Pharmaceutical and Medical Research, 4 (10), 227-234.

Memon, A.H., Ismail, Z., Al-Suede, F.S.R., Aisha, A.F.A., Hamil, M.S.R., Saeed, M.A.A., Laghari, M., \& Majid, A.M.S.A. (2015). Isolation, characterization, crystal structure elucidation of two flavanones and simultaneous RP-HPLC determination of five major compounds from Syzygium campanulatum Korth. Molecules, 20, 14212-14233. 
Muharni, M., Fitrya, F., Ruliza, M.O., Susanti, D.A., \& Elfita, E. (2014). Di-(2-ethylhexyl)phthalate and pyranone derivated from endophytic fungi Penicillium sp the leave of Kunyit Putih (Curcuma zedoaria). Indonesian Journal of Chemistry, 14 (3), $290-296$.

Procházková, D., Boušová, I., \& Wilhelmová, N. (2011). Antioxidant and prooxidant properties of flavonoids. Fitoterapia, 82, 513-523.

Santoyo, G., Hagelsieb, M.G., Mosqueda, D.C.O.M., \& Glick, B.R. (2016). Plant growth-promoting bacterial endophytes. Microbiological Research, 183, 92-99.

Sawai, Y., \& Sakata, K. (1998). NMR Analytical Approach to Clarify the Antioxidative Molecular Mechanism of Catechins Using 1,1-Diphenyl-2picrylhydrazyl.

Journal of Agricultural and Food Chemistry, 46, 111-114.
Selvi, A.T., Joseph, G.S., \& Jayaprakasha, G.K. (2003). Inhibition of growth and aflatoxin production in Aspergillus flavus by Garcinia indica extract and its antioxidant activity. Food Microbiology, 20, 455-460.

White, T.J., Bruns, T.D., Lee, S.B., \& Taylor, J.W. (1990). Amplification and direct sequencing of fungal RNA genes for phylogenetics. In: Innis MA, Gelfand DH, Sninsky JJ, White TJ. (eds). PCR protocols. Academic; San Diego, 315-322.

Yadav, M., Yadav, A., \& Yadav, J.P. (2014). In vitro antioxidant activity and total phenolic content of endophytic fungi isolated from Eugenia jambolana Lam. Asian Pacific Journal of Tropical Medicine, 7 (Suppl 1), S256-S261.

Yohandini, H., Julinar, J., \& Muharni, M. (2015). Isolation and phylogenetic analysis of thermophile community within Tanjung Sakti hot spring, South Sumatera,Indonesia.Hayati Journal of Biosciences, $22,143-148$. 